\title{
Vivendo com insuficiência renal: obstáculos na terapia da hemodiálise na perspectiva das pessoas doentes e suas famílias
}

\author{
I ${ }^{1}$ Francisco Javier Mercado-Martinez, ${ }^{2}$ Denise Guerreiro Vieira da Silva, \\ ${ }^{3}$ Sabrina da Silva de Souza, ${ }^{4}$ Juliana Graciela Vestana Zillmer, ${ }^{5}$ Soraia Geraldo \\ Rozza Lopes, ${ }^{6}$ Julia Estela Böell I
}

Resumo: O princípio do Sistema Único de Saúde do Brasil é assegurar à população o direito a uma atenção à saúde universal, integral e gratuita, incluindo as pessoas com insuficiência renal. $\mathrm{O}$ objetivo desta pesquisa foi examinar as perspectivas das pessoas com doença renal crônica e seus familiares sobre os obstáculos enfrentados no acesso à terapia de hemodiálise. Foi realizado estudo qualitativo em um hospital público localizado no sul do Brasil. Utilizando uma amostragem teórica, 11 pessoas em hemodiálise e cinco familiares foram selecionados. Os dados foram obtidos mediante entrevistas semiestruturadas e realizou-se análise de conteúdo convencional. Os resultados mostraram que os participantes manifestavam ter recebido bom atendimento dos profissionais de saúde no tratamento de hemodiálise. Além das sessões de hemodiálise, eles também reconheciam o acesso gratuito a medicamentos, exames, hospitalizações, transporte, alimentação e outros. No entanto, enfrentavam carências e dificuldades pela falta de profissional médico, medicamentos e materiais básicos de diagnóstico. Por isso, aqueles com mais recursos econômicos optavam pela medicina privada, consultando especialistas, comprando medicamentos e realizando exames mais rapidamente. Conclui-se que os obstáculos no acesso à terapia de hemodiálise repercutem negativamente na atenção à saúde das pessoas com DRC e acentuam as desigualdades sociais.

> Palavras-chave: insuficiência renal; hemodiálise; inequidades; pesquisa qualitativa; Brasil.

\author{
1 Universidade de Guadalajara, \\ Departamento de Saúde \\ Pública. Guadalajara, Jalisco, \\ México. Endereço eletrônico: \\ francisco.mercado@cucs. \\ udg. $m x$ \\ 2 Universidade Federal de \\ Santa Catarina, Programa de \\ Pós-Graduação. Florianópolis- \\ SC, Brasil. Endereço eletrônico: \\ denise.guerreiro@ufsc.br \\ ${ }^{3}$ Hospital Universitário, \\ Emergência Adulto. \\ Florianópolis-SC, Brasil. \\ Endereço eletrônico: \\ enfermeirasabrina@gmail.com \\ ${ }^{4}$ Hospital Universitário, \\ Emergência Adulto. \\ Florianópolis-SC, Brasil. \\ Endereço eletrônico: \\ enfermeirasabrina@gmail.com \\ ${ }^{5}$ Universidade Federal de \\ Santa Catarina, Programa de \\ Pós-Graduação. Florianópolis- \\ SC, Brasil. Endereço eletrônico: \\ soraia.gr.lopes@gmail.com \\ ${ }^{6}$ Universidade Federal de \\ Santa Catarina, Programa de \\ Pós-Graduação. Florianópolis- \\ SC, Brasil. Endereço eletrônico: \\ juliaestela_8@hotmail.com
}

Recebido em: 19/03/2014 Aprovado em: 02/12/2014 
A doença renal crônica (DRC) é considerada uma pandemia ou um problema global de saúde pública (GLASSOCK; WINEARLS, 2011; SALGADO FILHO, 2009). Essa epidemia em nível mundial tem sido explicada pelo excessivo crescimento no número de pessoas com diabetes, hipertensão arterial e obesidade, assim como pelo aumento na expectativa de vida da população (MOLITCH et al., 2003; HAMER; EL NAHAS, 2006). Os dados são imprecisos, mas estima-se que o número de pessoas com diabetes passará de 171 milhões no ano 2000 a 366 milhōes no ano 2030. Isto, portanto, poderá aumentar significativamente os casos novos de DRC (DAVIDS, 2007).

Segundo os profissionais da saúde, os avanços tecnológicos e terapêuticos dos tratamentos da DRC contribuíram para melhorar a qualidade de vida e o aumento da sobrevida das pessoas com esta condição crônica (MARTINS; CESARINO, 2005). Das terapias existentes na atualidade, o transplante renal é considerado a melhor opção. No entanto, a hemodiálise é a terapia mais utilizada em nível mundial devido, entre outros, aos problemas diversos que enfrentam os programas de transplantes, pela falta de órgãos e uma estrutura inadequada para captá-los e aproveitá-los (GARCIA; HARDEN; CHAPMAN, 2012).

No mundo inteiro, tem havido incremento no acesso às terapias renais nos últimos anos. Contudo, persistem dificuldades no acesso, sobretudo nos países de média e baixa renda (RISVI et al., 2003). Situação diferente parece ocorrer em países onde a população tem acesso a um sistema universal de saúde. Com exceção dos Estados Unidos, a maioria dos países desenvolvidos dispõe de um sistema com acesso gratuito às terapias renais a toda a população. No caso latino-americano, Argentina, Brasil, Costa Rica, Cuba, Uruguai e Venezuela também dispõem de um sistema de cobertura universal a cargo do Estado (MIZRAJI et al., 2007). Algumas evidências sugerem, contudo, que mesmo em países com um sistema de proteção social em saúde, persistem desigualdades no acesso, utilização e resultados da atenção médica, particularmente nas terapias renais: diálise peritoneal, hemodiálise e transplante. Por exemplo, a mortalidade é maior na Argentina em pessoas em hemodiálise com poucos recursos econômicos em comparação com aqueles com maiores recursos (MARINOVICH et al., 2012). Da mesma maneira, no 
Reino Unido encontrou-se associação entre baixa condição socioeconômica e maior mortalidade em pessoas em diálise (CASKEY et al., 2006).

O assunto é particularmente de interesse no Brasil, que enfrenta complexos desafios no controle das doenças crônicas, incluindo a insuficiência renal (LESSA, 2004), no contexto do Sistema Único de Saúde (SUS) e desigualdade social persistente (CHOR, 2013). O número estimado de pessoas em diálise no país foi de 91.314 em 2011, dos quais $90 \%$ estavam em hemodiálise (SESSO et al., 2011). A atenção às pessoas com DRC é uma das áreas de competência do SUS. De acordo com as disposições oficiais, a atenção às pessoas com esta doença inclui acesso universal e gratuito às terapias renais, incluindo: diálise peritoneal, hemodiálise, e/ou transplante renal; medicamentos básicos e excepcionais da assistência farmacêutica; consultas médicas e com outros profissionais da saúde; transporte; acesso a internação hospitalar quando necessário; e equidade em lista de espera para transplante renal (SILVA et al., 2011).

Apesar das disposiçóes oficiais, várias dificuldades têm sido reportadas na atenção a pessoas com DRC. Um estudo apontou menor gasto com medicamentos com pessoas com DRC que residiam em municípios de menor índice de desenvolvimento humano (SILVA et al., 2011). Disparidades regionais acentuadas também foram indicadas em relação aos transplantes (MEDINA-PESTANA JR. et al, 2011) e 61,5\% dos participantes de um estudo afirmaram haver necessidade de mudanças nos serviços de hemodiálise (COUTINHO; TAVARES, 2011).

Considerando esta situação, desenvolvemos um estudo que teve como objetivo examinar as perspectivas das pessoas com DRC e seus familiares sobre os obstáculos enfrentados na terapia de hemodiálise. O mesmo foi orientado pela questão: Quais são as facilidades ou dificuldades que as pessoas com DRC enfrentam na terapia da hemodiálise? Nosso interesse nesta pesquisa está centrado no uso de tecnologias em saúde, neste caso a hemodiálise, mas do ponto de vista dos próprios usuários e suas famílias.

\section{Metodologia}

Este artigo faz parte de uma pesquisa qualitativa desenvolvida num hospital universitário de uma universidade pública localizada em uma cidade do Sul 
do Brasil. A estratégia qualitativa foi adotada porque é idônea para explorar as dimensões subjetivas, perspectivas, experiências, os significados e as práticas discursivas da população (BOSI; MERCADO, 2007).

As pessoas que participaram do estudo compuseram dois grupos: a) pessoas com DRC; e b) familiares. A partir da amostragem teórica (KUZEL, 1992), foram selecionadas 11 pessoas e cinco familiares. O critério para a sua inclusão foi que as pessoas com DRC estivessem no tratamento de hemodiálise por mais de seis meses e que os familiares fossem seus acompanhantes. A idade dos primeiros oscilava entre 26 e 80 anos, cinco eram homens e seis mulheres; sete estavam casados, três eram viúvos e uma divorciada. Eles tinham, em média, 4,3 anos em diálise, além de terem outras doenças crônicas, sobretudo diabetes mellitus e hipertensão arterial. Excetuando duas de classe média, as demais pessoas eram de nível socioeconômico baixo.

Os dados foram coletados no hospital entre setembro de 2011 e janeiro de 2012, por meio de entrevistas semiestruturadas com pessoas com DRC e seus familiares no serviço de hemodiálise. A escolha dessa abordagem foi porque a mesma permite aos participantes decidirem o que querem contar de sua história e como deve ser contada. Os participantes foram incentivados a falarem de suas histórias em relação à doença e à atenção a saúde que vinham recebendo. As questôes iniciais utilizadas pelos pesquisadores foram do tipo: "Poderia me contar desde que você começou com a doença?". Ou: "O que fez para cuidar de sua saúde?". A entrevista foi dividida em quatro fases: a) abertura (apresentação; agradecimentos; apresentação dos objetivos do estudo; objetivos e dinâmica da entrevista; e abertura para perguntas dos entrevistados); b) exploração da experiência da doença (começo; causas; manifestações; efeitos; etc.); c) o processo da atenção a DRC (a busca da atenção; sucessos; facilidades e obstáculos); d) encerramento (síntese; perguntas sobre dados adicionais; perguntas aos pesquisadores; e agradecimentos).

As entrevistas foram gravadas e complementadas com notas das observações; posteriormente foram transcritas de acordo com regras preestabelecidas. As mesmas foram capturadas no programa Ethnograph. Os dados foram analisados mediante análise de conteúdo convencional (HSIEH; SHANNON, 2005). O processo consistiu na leitura repetida do texto e imersão nos dados para ter uma visão do conjunto e permitir a elaboração dos códigos, temas 
centrais e posteriormente das categorias. Resultaram desse processo de análise as seguintes categorias: "As terapias funcionam, se estiver dentro do serviço"; "O primordial é uma boa atenção"; "O diagnóstico tardio"; "O transporte é gratuito, mas demorado"; "Agilidade nas consultas particulares"; "Instabilidade na disponibilidade de medicamentos e realização de exames"; e "A hemodiálise como prisão".

Quanto aos aspectos éticos formais, foi solicitado o consentimento dos participantes, comunicando que poderiam desistir a qualquer momento. Sob nenhuma circunstância foi pedido aos participantes para continuarem a entrevista, caso se sentissem desconfortáveis ou ameaçados. $\mathrm{O}$ projeto foi aprovado pelo Comitê de Ética em Pesquisa com Seres Humanos de uma Universidade Federal, com certificado número 2263 e atendeu à Resolução 196/96 do Conselho Nacional de Saúde, vigente na ocasião da pesquisa.

\section{Resultados}

As pessoas com DRC e seus familiares entrevistados adotaram uma postura na qual reconheceram ter recebido uma boa atenção nos serviços de saúde, referente ao tratamento realizado pelos profissionais da saúde. No entanto, também referiram enfrentar diversos obstáculos e carências durante o processo da hemodiálise, desde o momento do diagnóstico até a realização das sessões dialíticas e a obtenção de alguns insumos para o tratamento.

\section{As terapias funcionam, se estiver dentro do serviço}

As pessoas em hemodiálise precisavam ir até o serviço de diálise no hospital. Elas realizavam as terapias de hemodiálise duas ou três vezes na semana. Algumas iam segunda, quarta e sexta-feira; outras, terça e quinta-feira. Algumas iniciavam às sete horas da manhã, outras às 11 e outras às 15 horas. As sessões, em geral, eram de três horas, algumas com duração de duas horas e meia. Devido ao número restrito de sete máquinas existentes no serviço, o número de pessoas que frequentavam o serviço de hemodiálise oscilava entre 20 e 25 . Este número era variável devido às hospitalizaçôes, transplantes e óbitos.

As dificuldades em entrar no serviço de hemodiálise eram múltiplas, sobretudo pela falta de máquinas e, consequentemente, a inexistência de vagas; mas uma vez inseridas no serviço, as pessoas com DRC tendiam a ter o tratamento garantido. 
Algumas pessoas solicitavam mudanças nos horários, sobretudo aqueles que realizavam suas sessões no período da tarde. O motivo mais frequente era terem mais facilidade de transporte neste horário ou devido a suas atividades laborais. Essas solicitações eram atendidas de acordo com a disponibilidade do serviço, em geral, quando uma pessoa morria ou recebia o transplante.

\section{O primordial: uma boa atenção}

A maioria das pessoas entrevistadas referenciou sua satisfação pela qualidade da atenção que recebia por parte dos profissionais da saúde, particularmente dos médicos, das enfermeiras, em especial daqueles que trabalhavam na unidade de hemodiálise, mas também nos diferentes níveis do SUS, tanto nas unidades básicas de saúde como nos hospitais. Segundo os termos que utilizavam comumente, eles sempre recebiam uma "boa atenção", da qual não podiam reclamar ou ter queixa alguma. Múltiplas eram as razões pelas quais essas pessoas e seus familiares manifestavam-se satisfeitas com a atenção que recebiam, destacando o tratamento afetuoso por parte dos profissionais da saúde. Além disso, reconheciam como positivo o acesso gratuito às sessões de hemodiálise, ao transporte, às consultas, aos medicamentos, aos exames, à hospitalização e, inclusive, as refeições recebidas durante ou após a sessão de hemodiálise. Um homem expôs algumas das razões pelas quais ficava satisfeito com a atenção:

Eu estava sendo atendido por uma das melhores casas que tem no Brasil, a ... de Porto Alegre, e não tem o que dizer de lá. Mas aqui (no hospital) é muito melhor... A rapidez com que as coisas acontecem aqui é mais presteza, entende? Tu tens que fazer um exame, você tem que fazer aquilo, as coisas funcionam. As pessoas são atenciosas contigo e te escutam e isso é muito importante... Tu falas e as pessoas te ouvem... eu achei muito bom isso. Até eu não esperava isso do serviço público para ser sincero... eu não tenho o que dizer do serviço público...

\section{O diagnóstico tardio}

Várias foram as referências feitas pelos participantes sobre o início da atenção ao problema renal. Por um lado, metade deles foi diagnosticada pelos médicos particulares, e outra metade, pelos profissionais dos hospitais públicos. Mas a maioria deles não foi diagnosticada oportunamente, o que acarretou em apresentar a insuficiência renal já em estado avançado. E também, uma vez feito o diagnóstico, os médicos indicaram a hemodiálise pela gravidade da situação 
das pessoas. Vários afirmaram ter rejeitado a proposta inicial da fístula, porque os impediria de trabalhar ou por motivos estéticos.

\section{O transporte é gratuito, mas demorado}

Vários participantes residiam na cidade onde estavam realizando a terapia da hemodiálise; outros vinham de localidades mais distantes, mas todos da região metropolitana. Apenas um contava com automóvel próprio, motivo pelo qual a maioria precisava de transporte público. Neste caso, recebiam auxílio das prefeituras municipais, mediante o programa Tratamento Fora de Domicílio (TFD). Com esse programa, um carro ou ambulância os transportava para o hospital e de volta para a sua casa, duas ou três vezes na semana. $\mathrm{O}$ transporte estava disponível todos esses dias, sem custo algum para as pessoas ou familiares acompanhantes. Uma familiar fez referência ao apoio recebido pela prefeitura com o transporte:

E agora nós estamos aqui (no hospital). A Secretaria (do município) está ajudando bastante; está trazendo nós para cá e levando e assim a gente vai tocando o barco de pouquinho em pouquinho. A gente atinge o orçamento que é a cura dele... A Secretaria não estava ajudando na época (passada). Agora que eles começaram com o carro a circular por lá (no bairro) daí foram buscar um de nós, levaram agora... Agora está rolando tudo certo, está dando tudo certo.

No entanto, segundo vários outros testemunhos, a utilização do transporte público apresentava dificuldades. Algumas prefeituras pequenas contavam com poucos carros e motoristas e nem sempre havia transporte disponível em todos os horários. O comum era terem transporte no período matutino para os hospitais e o retorno para suas residências à tarde. Por isso, as pessoas que faziam a hemodiálise pela manhã precisavam ficar aguardando no hospital o transporte de retorno para sua casa. Aqueles que faziam hemodiálise à tarde precisavam ir pela manhã para garantir o transporte de ida, mas caso perdessem o transporte de retorno deveriam retornar para suas residências com seus próprios meios.

Uma situação particularmente problemática, sobretudo para as pessoas idosas, era o número de horas que durava todo esse processo, desde o momento de saída de casa até o retorno, podendo chegar a dez horas ao dia, com um total de 30 horas semanais. Além disso, tinham como complicador os efeitos frequentes após a sessão: mal-estar (fraqueza, sono e náuseas) que alguns sentiam e se agravava com o transporte. Uma mulher, com quase 70 anos, descreveu em termos pessimistas sua situação pela utilização do transporte oferecido pela prefeitura: 
A maioria das pessoas era acompanhada ao hospital pelos familiares para as sessões de hemodiálise. Em geral, as pessoas idosas precisavam do acompanhamento de um familiar, diferentemente dos mais jovens. O familiar e a pessoa em tratamento viajavam no transporte da prefeitura sem pagamento algum; mas esse acompanhamento podia ter efeitos negativos na renda da família, porque o acompanhante não trabalhava nos dias da hemodiálise.

\section{Agilidade, mas nas consultas particulares}

Houve unanimidade entre os participantes que os profissionais de saúde tratavam bem e dispensavam a atenção necessária durante as consultas no posto de saúde e no hospital, como já colocado anteriormente. Entretanto, essas pessoas e seus familiares enfrentavam diversas dificuldades na realização de consultas com especialistas pelo distanciamento entre a atenção primaria e a atenção especializada. Mesmo no serviço de hemodiálise faltava médico nefrologista. A falta de especialistas nefrologistas tinha dois efeitos: por um lado, o tempo das interconsultas era muito longo; ou seja, o tempo de espera entre a consulta no posto de saúde e a consulta com o especialista; o mesmo sucedia com as interconsultas com outros especialistas. $\mathrm{O}$ número reduzido de nefrologistas também aumentava o tempo de espera das consultas. Uma pessoa em tratamento de hemodiálise exemplificou alguns dos problemas que enfrentava:

Eu sou muito bem atendido, eles atendem a gente muito bem. O que a gente precisar,
eles estão prontos a atender, não tem nada para reclamar não, do pessoal daqui nunca
tive nada nenhuma reclamação... Mas agora não tenho médico. Tem que esperar que
chame lá embaixo (área de consulta) um médico para vir aqui atender. E a gente fica
ai horas e horas pronto para ir embora, mas tem que esperar para o médico vir lá de
baixo. Até agora tinham três médicos e agora só tem um. [...] Às vezes, a gente consegue
a consulta, mas aqui está meio ruim de médico; a gente precisa de uma receita e tem
vezes que fica o pedido de uma receita ai dois, três dias. Às vezes, a gente pede na terça
só vai ser coisa na outra terça-feira porque a gente não tem médico e o médico não vem...

\section{Instabilidade na disponibilidade de medicamentos e realização de exames} As pessoas entrevistadas assinalaram também que, com frequência, não recebiam medicamentos, pela falta destes nos postos de saúde, farmácias ou 
hospitais públicos. Por esta razão, aqueles sem recursos econômicos precisavam ir várias vezes às farmácias, até conseguir, ou, em alguns casos, abandonavam o tratamento médico durante dias. Em outras ocasiōes, aqueles sem dinheiro para comprar remédios contavam com a solidariedade de outras pessoas que já estavam no programa de hemodiálise em um empréstimo de medicação. Além disso, o serviço também dispunha de medicamentos doados por familiares de outras pessoas que foram a óbito ou de reservas próprias do serviço e forneciam esses medicamentos às pessoas que não tinham conseguido obter. No entanto, aqueles com mais recursos econômicos adquiriam os medicamentos nas farmácias privadas e continuavam o tratamento médico. Um participante se referiu aos custos feitos tanto das drogas como dos exames:

Eu gastei muito com remédio. Meu Deus do céu! Não vou nem lhe contar o que eu gastei com remédio e exame...

Os exames eram considerados parte importante do tratamento e da vida dos participantes da pesquisa. Mas quando o médico indicava a necessidade de realizar exames, um problema recorrente era a demora na sua realização que, em alguns casos, podia ser de vários meses. Nestas circunstâncias, aquelas pessoas com recursos financeiros próprios resolviam o problema pagando com seus recursos nos serviços de saúde particular. No entanto, aquelas sem recursos esperavam meses até realizar o exame no lugar programado. Um dos participantes fez uma descrição detalhada da situação e da forma como era solucionado o problema com seus recursos:

Eu tive que pagar muitos exames que demoravam muito... 3, 4 meses..., "para março é para não sei quando". Eu estava mal e digo "não vou aguentar". E ai eu conversei com uma médica lá e digo "doutora, eu estou com um problema sério..." E ela me deu uma série de exames e eu fui para marcar e era tudo não sei para quando. E eu voltei e falei com ela: "doutora, e se eu puder fazer esses exames e trouxer para a senhora avaliar o meu estado, a senhora aceita?” Daí ela disse "se tu podes fazer, tu faz e traz para mim que daí a gente dá uma olhada... E... daí ela me deu uma série de exames e fui e peguei. Quando tem a facilidade de ter um dinheirinho para ir ali fazer, faz já, faz de manhã e a tarde já está pronto... Porque se tu vais esperar muito, não alcanças, não chegas lá. Esse é o problema... Então, quando a gente pode se desatar por outro caminho e agilizar as coisas, vamos fazer, né? Porque afinal de contas o importante é a gente...

\section{A bemodiálise como prisão}

As pessoas participantes, sobretudo as mulheres, faziam referência aos efeitos do tratamento da hemodiálise na sua condição, e particularmente na sua vida 
diária. Para elas, a hemodiálise passou a significar uma vida restrita e controlada, como numa prisão. Sentiam-se prisioneiras pelo compromisso de ir três vezes por semana ao serviço de nefrologia para realizar a hemodiálise e ficar várias horas diárias sentadas numa cadeira e ligadas a uma máquina. Passavam a se sentir dependentes de uma máquina que não era controlada por elas mesmas, mas pelos profissionais de saúde, que passavam a exercer controle sobre suas vidas, incluindo até mesmo o que e o quanto poderiam comer, beber ou viajar.

$\mathrm{O}$ processo da hemodiálise exigia paralelamente o abandono das atividades laborais e sociais. Juntamente com a perda do trabalho, os participantes tinham uma redução das atividades recreativas, como viagens ou festas. O sonho de viajar para outros estados e até países estava sempre presente. Entretanto, para viajar dependiam de vagas em outros serviços de diálise no próprio país, que poderia ser autorizada ou não pelos profissionais de saúde do serviço, considerando a capacidade do serviço de hemodiálise do hospital da outra cidade.

\section{Discussão}

Uma característica predominante do discurso dos participantes desta pesquisa foi que eles recebiam uma boa atenção na terapia de hemodiálise. Esta constatação parece estar baseada no bom atendimento recebido dos profissionais da saúde, assim como pelo acesso gratuito a esta terapia renal, apesar de alguns problemas enfrentados no acesso e uso dos serviços. Esses resultados são discrepantes em relação aos de outro estudo realizado na mesma região, que registrou, basicamente, queixas e reclamações dos usuários pelos serviços recebidos no SUS (BACKES et al., 2009). No entanto, nossos achados concordam com os resultados de uma pesquisa desenvolvida em outra região do país, onde os usuários estão satisfeitos com o atendimento recebido, embora tenham apresentado queixas quanto à lentidão no referenciamento para os hospitais (ARAKAWA et al., 2012).

De acordo as disposições oficiais do Brasil, todas as pessoas com insuficiência renal têm direito a uma atenção universal, gratuita, integral e igualitária (BRASIL, 2004). Os participantes desta pesquisa relataram ter recebido uma atenção gratuita, mas com carências de recursos humanos, materiais e medicamentos no acesso e tratamento da hemodiálise. Ou seja, eles não recebiam atenção adequada e integral decorrente de diversas 
carências: falta de médicos especialistas, recursos para fazer exames no momento necessário, transporte oportuno, assim como medicamentos. Examinando a integralidade do cuidado nas unidades de hemodiálise, Fujii e Oliveira (2011) também reportaram dificuldades na rede de serviços de saúde no mesmo país. Entre essas dificuldades, apontam: falta de medicamentos; situações clínicas que impedem o uso do transporte; demora no acesso a exames e as consultas com especialistas; assim como um número reduzido de pessoas no serviço. Nossos resultados também são semelhantes aos encontrados por outros autores cuja pesquisa focalizou a atenção de outras doenças crônicas no Brasil. Por exemplo, Trad et al. (2010) encontraram que as pessoas com hipertensão arterial enfrentavam dificuldades nas consultas e na aquisição dos medicamentos.

A carência de recursos humanos e materiais no processo de atenção na hemodiálise em um hospital público parece favorecer, por sua vez, as desigualdades entre as pessoas com DRC. Aquelas pessoas com mais recursos econômicos vão para consulta com o médico especialista particular, fazem os exames prontamente em unidades particulares e compram os medicamentos nas farmácias privadas, além de reduzir o tempo de transporte e espera das sessões por terem seu próprio carro. No entanto, as pessoas sem recursos financeiros esperam mais tempo para consultar com o especialista do SUS, para receber e, consequentemente, consumir os medicamentos e realizar os exames necessários.

Situação semelhante foi reportada por Martínez e colaboradores (MARTÍNEZ et al., 2011). Os autores relataram que as pessoas com DRC economicamente desfavorecidas são usuárias do SUS, são mais jovens, têm menor grau de escolaridade e, além de estarem por mais tempo no tratamento de hemodiálise e ter menor conhecimento sobre as terapias renais substitutivas, têm maior dificuldade no acesso ao tratamento especializado. Os resultados evidenciam que as desigualdades sociais não desaparecem com a proposição de um sistema de saúde gratuito e universal. A falta de medicamentos e recursos humanos nesta terapia renal não teria efeitos diferentes entre as pessoas com DRC, segundo sua condição socioeconômica, se a implantação do sistema de saúde assegurasse a disponibilidade constante e igualitária dos recursos humanos e materiais. 
A falta de recursos materiais e humanos nos serviços públicos não só incrementa as desigualdades entre as pessoas, mas também favorece a utilização dos serviços privados de saúde. De acordo com os resultados mostrados, a utilização dos serviços privados foi observada durante todo o processo de atenção da hemodiálise. Por exemplo, metade das pessoas foi diagnosticada no serviço privado. Situação semelhante ocorria com as consultas com os especialistas, com a realização dos exames e com a aquisição de medicamentos.

A utilização do sistema privado tem origem na carência de recursos humanos e materiais suficientes no sistema público de saúde e nas diferenças no acesso aos recursos econômicos entre a população. Achados semelhantes têm sido relatados em diversos estudos, indicando a contratação de serviços privados pelo SUS para a realização da diálise, como por exemplo, o trabalho de Nardino \& Krüger (2007). Do nosso ponto de vista, o problema não está na combinação do público e do privado per se; o conflito aparece quando as pessoas se veem obrigadas a utilizar o serviço privado, pela incapacidade do serviço público de prover a atenção e, consequentemente, as pessoas precisam pagar pelos serviços a que têm direito.

Os resultados do presente estudo não podem ser generalizados; no entanto, eles podem ser fontes de inspiração para outras pesquisas. Entre outras, se esses resultados correspondem a uma das regiôes com maior desenvolvimento do Brasil, qual é a situação das regiōes menos desenvolvidas? Os participantes frequentemente disseram que não queriam reclamar ou se queixar dos serviços ou da equipe de saúde. Um estudo futuro poderia examinar os significados de tais expressões, seguindo algumas perguntas de trabalho: não reclamar é um traço cultural do sul do Brasil? Ou constitui uma evidência do medo de punição dos profissionais da saúde? Por último, os entrevistados evidenciaram ter gastos diretos e indiretos nesta terapia renal. Em relação a estes dados, quais são os custos financeiros totais para as pessoas doentes e as famílias?

Esta investigação teve algumas limitações, como o fato de se restringir aos discursos dos participantes, o que pode ter excluído outras dimensóes da problemática. Por exemplo, seria pertinente incluir observações sobre como os medicamentos são disponibilizados nos serviços de saúde, para compreender melhor a magnitude da falta de medicamentos a que os participantes se referiram. O estudo também se limitou a um hospital universitário, podendo 
dar uma ideia distorcida do que acontece com a maioria dos hospitais públicos. Por outro lado, ao entrevistar apenas as pessoas em hemodiálise e suas famílias, ignora as vozes de outros atores importantes do problema que precisariam ser pesquisadas, entre elas dos tomadores de decisão, os gestores e os profissionais de saúde.

As evidências apresentadas neste estudo parecem indicar que o tratamento da hemodiálise não atende de forma integral, gratuita ou igualitária as pessoas com DRC de acordo aos princípios do SUS. Apesar do SUS, as desigualdades persistem na atenção de pessoas com problemas renais dependendo de seus recursos financeiros. Esses resultados têm implicações não apenas para o reconhecimento da situação sanitária das pessoas com DRC e seus familiares, mas também trazem indicações dos desafios que o SUS enfrenta na implementação de uma atenção à saúde capaz de reduzir as desigualdades sociais entre a população.

\section{Considerações finais}

Mediante uma aproximação qualitativa, esta pesquisa focalizou a atenção dada às pessoas com DRC no processo da terapia de hemodiálise num país com acesso universal ao sistema de saúde. Nossos resultados, contudo, não pretendem ser representativos do que acontece no Brasil ou no estado onde a pesquisa foi desenvolvida. A análise dos achados e as conclusões dos mesmos devem considerar que se trata de uma investigação realizada num hospital universitário, de uma cidade de médio porte do sul do país, e de uma das regiōes com maior desenvolvimento no mesmo país.

A contribuição deste estudo consiste no exame de um tema pouco explorado em países com acesso universal aos serviços de saúde e também porque suscita outros estudos, como por exemplo, as diferenças entre a adesão ao tratamento de pessoas em diferentes condições socioeconômicas.

Conclui-se que as carências e as dificuldades no acesso e uso da terapia hemodialítica repercutem negativamente na atenção das pessoas com DRC. Isso expressa que as desigualdades entre as pessoas doentes ainda estão presentes na atenção em saúde, ou seja, mesmo com uma proposta de equidade na saúde no SUS, persistem as desigualdades aqui apontadas. Nesse sentido, medidas de superação dessas carências e desigualdades deveriam estar mais explícitas nas políticas e programas de saúde de atenção a saúde das pessoas com DRC. ${ }^{1}$ 


\section{Referências}

ARAKAWA, A. M. et al. Percepção dos usuários do SUS: expectativa e satisfação do atendimento na Estratégia de Saúde da Família. Rev CEFAC, v. 14, n. 6, p. 1108-1114, 2012. BACKES, D. S. et al. O que os usuários pensam e falam do Sistema Único de Saúde? Uma análise dos significados à luz da carta dos direitos dos usuários. Cien Saude Colet, v. 14, n. 3, p. 903-910, 2009.

BOSI, M. L. M.; MERCADO, F. J. Pesquisa qualitativa de serviços de saúde. Petrópolis: Vozes, 2007, 607p.

BRASIL. Ministério da Saúde. Portaria GM/MS n. 1168, de 15 de junho de 2004. Institui a Política Nacional de Atenção ao Portador de Doença Renal. Brasília: Ministério da Saúde, 2004. Disponível em: http://bvsms.saude.gov.br/bvs/publicacoes/portaria_1168_ac.htm Acesso em: 10 jan. 2013.

CASKEY, F. J. et al. Social deprivation and survival on renal replacement therapy in England and Wales. Kidney Int, v. 70, n. 12, p. 2134-2140, 2006.

CHOR, D. Desigualdades no Brasil: é preciso ter raça. Cad Saúde Pub, v. 29, n. 7, p. 12721275, 2013.

COUTINHO, N. P. S.; TAVARES, M. C. H. Atenção ao paciente renal crônico, em hemodiálise, sob a ótica do usuário. Cad Saúde Coletiva, v. 19, n. 2, p. 232-239, 2011.

DAVIDS, M. R. The global epidemic of chronic kidney disease. SA Heart, v. 4, n. 3, p. 10-15, 2007.

FUJI, C. D. C.; OLIVEIRA, D. Fatores que dificultam a integralidade no cuidado em hemodiálise. Rev. Lat-Am Enfermagem, v. 19, n. 4, p. 953-959, 2011.

GARCIA, G.; HARDEN, P.; CHAPMAN, J. O papel global do transplante renal. J Bras Nefrol, v. 34, n.1, p. 1-7, 2012.

GLASSOCK, R. J.; WINEARLS, C. An epidemic of chronic kidney disease: fact of fiction? Nephrol Dyal Transplant, v. 23, n. 4, p. 1117-1121, 2008.

HAMER, R. A.; EL NAHAS, A. M. The burden of chronic Kidney disease: is rising rapidly worldwide. $B M J, v .332$, n. 7541, p.563-564, 2006.

HSIEH, H. F.; SHANNON, S. E. Three approaches to qualitative content analysis. Qual Health Res, v. 15, n. 9, p. 1277-1288, 2005.

KUZEL, A. J. Sampling in qualitative inquiry. En: Crabtree BF y Miller WL. Doing qualitative research. Newbury Park: Sage, p. 31-44, 1992.

LESSA, I. Doenças crônicas não transmissíveis no Brasil: um desafio para a complexa tarefa da vigilância. Cien Saude Colet, v. 9, n.4, p. 931-943, 2004.

MARINOVICH, S. et al. The lack of income is associated with reduced survival in chronic haemodialysis. Rev Nefrol, v. 32, n. 1, p. 79-88, 2012. 
MARTÍNEZ, B. B. et al. Desigualdade social em doentes renais crônicos. Rev Bras Clin Med, v. 9, p. 3, p. 195-199, 2011.

MARTINS, M. R. I.; CESARINO, C. B. Qualidade de vida de pessoas com doença renal crônica em tratamento hemodialítico. Rev Lat-Am. Enfermagem, v. 13, n. 5, p. 2005 set-out. Acesso em: 10 jan. 2013.

MEDINA-PESTANA, J. O. et al. O contexto do transplante renal no Brasil e sua disparidade geográfica. J Bras Nefrol, v. 33, n. 4, p. 472-484, 2011.

MIZRAJI, R. et al. Organ donation in Latin America. Transplantation Proceedings, v. 39, n. 2, p. 333-335, 2007.

MOLITCH, M. E. et al. The diabetes prevention program and its global implications. $J \mathrm{Am}$ Soc Nephrol, v. 14, n. 7, supl. 2, p. S103-S107, 2003.

NARDINO, D.; KRÜGER, T. R. O serviço privado contratualizado pelo SUS: o caso da diálise. Revista Grifos, v. 22, n. 23, p. 299-318, 2007.

RISVI, S. A. H. et al. Renal transplantation in developing countries. Kidney Int, v. 63, supl 83, p. S96-S100, 2003.

SALGADO FILHO, N.; BRITO, D. J. A. Doença renal crônica: a grande epidemia deste milênio. J Bras Nefrol, São Paulo, v. 28, n. 3, p.1-5, 2009.

SESSO, R. et al. Relatório do censo brasileiro de diálise de 2011. J Bras Nefrol, v. 34, n. 3, p. 272-277, 2012.

SILVA, G. D. et al. Medicamentos excepcionais para doença renal crônica: gastos e perfil de utilização em Minas Gerais, Brasil. Cad Saúde Pub, v. 27, n. 2, p. 357-368, 2011.

TRAD, L. A. B. et al. Itinerários terapêuticos face à hipertensão arterial em famílias de classe popular. Cad Saúde Púb, v. 26, n. 4, p. 797-806, 2010.

\section{Nota}

1 F.J. Mercado participou da concepção original e desenho do projeto, coleta de dados, análise e interpretação da informação, elaboração do artigo e aprovação da versão final. D. Guerreiro participou da concepção original e desenho do projeto, revisão dos dados, análise e interpretação da informação, elaboração do artigo e aprovação da versão final. S.S. Souza participou da discussão e reelaboração do projeto original, discussão e propostas para redefinir o desenho do projeto, coleta de dados, revisão dos dados, transcrição e manejo da informação, revisão crítica do artigo e revisão da versão final. J.V. Zillmer participou da discussão e reelaboração do projeto original, discussão e propostas para redefinir o desenho do projeto, coleta de dados, revisão crítica do artigo e revisão da versão final. S.R. Lopes participou da discussão e reelaboração do projeto original, discussão e propostas para redefinir o desenho do projeto, coleta de dados, revisão crítica do artigo e revisão da versão final. J.E. Böell participou da discussão e reelaboração do projeto original, discussão e propostas para redefinir o desenho do projeto, transcrição e manejo da informação, revisão crítica do artigo e revisão da versão final. 
Living with renal insufficiency: obstacles to hemodialysis treatment from the perspective of sick people and their families

One principle of the Brazilian National Health System (SUS) is to ensure free, comprehensive and equal health care to the population; including to those with chronic kidney disease. This study aimed to examine the perspectives of people living with renal insufficiency, and those of their families, regarding the obstacles faced while on hemodialysis treatment. A qualitative inquiry was conducted in a hospital located in a city from Southern Brazil. Using a theoretical sample, 11 sick people in hemodialysis and five relatives participated. Data was gathered using open interviews; conventional content analysis was used. Participants emphasized receiving good medical care from health professionals; besides having free access to hemodialysis sessions, consultations, medication, hospitalization, exams, transportation, and even meals. Nevertheless, they faced shortages and difficulties during the process due to lack of human personnel and inputs. Under such circumstances, renal sick people with more economic resources used private medicine, consulting specialists, buying medications and practicing exams more frequently than those with fewer resources. It is concluded that such obstacles have negative effects on health care, besides accentuating social inequalities.

> Key words: renal insufficiency; hemodialysis; inequalities; qualitative research; Brazil. 